\title{
The Assessment of Light Environment with the First Generation Leds
}

\author{
Olga E. Zheleznikova ${ }^{1}$, Svetlana A. Mikaeva ${ }^{2}$, Sergey N. Ageev $^{3}$, Ivan V. Blenstov ${ }^{4}$, Olga S. Voynova $^{5}$ \\ ${ }^{1,3,4,5}$ Federal State Budgetary Educational Institution of Higher Education, \\ National Research Ogarev Mordovia State University, Russia \\ ${ }^{2}$ Moscow Technological University, Russia
}

\begin{tabular}{l} 
Article Info \\
\hline Article history: \\
Received May 5, 2018 \\
Revised Jul 10, 2018 \\
Accepted Sep 6, 2018 \\
\hline Keyword: \\
Complex methodology \\
Experimental research facility \\
LED-based lighting \\
Lighting efficiency \\
Visual fatigue \\
Visual functions \\
Visual performance \\
\hline
\end{tabular}

\begin{abstract}
The article describes experimental studies on the effectiveness of lighting installations (LI) with light-emitting diodes (LEDs). It is established that LED-based lighting does not cause a negative impact on the organ of vision and the human body as a whole. The changes in the functional parameters of the organ of sight, which occur during the visual performance has the corresponding limits of physiological fluctuations and are reversible. The integral indicators of the efficiency of LED-based lighting were estimated. The practical significance of the results was shown.
\end{abstract}

Copyright $(0) 2018$ Institute of Advanced Engineering and Science. All rights reserved.

\section{Corresponding Author:}

Olga E. Zheleznikova,

Federal State Budgetary Educational Institution of Higher Education,

National Research Ogarev Mordovia State University, Russia.

Email: mehrdad.khosravi12@gmail.com

\section{INTRODUCTION}

Due to the rapid introduction of light emitting diodes (LEDs) as light sources (LS) for artificial illumination, a large number of questions, concerning the impact of their emission on the organ of vision and human body as a whole, appeared to be understudied. Anxiety about the safe use of LEDs for the purposes of general lighting is fully justified [1]-[6], since the possibility of LEDs using for creation of favorable lighting conditions requires supporting evidence. Herewith, such questions as the immediate hazard for the organ of sight, caused by LEDs radiation, and the possible consequences of prolonged exposure to artificial illumination of modern light sources for psychophysiological and physical health of people are significant. This gives grounds for consideration of conducted researches as actual. The energy savings may be large, the use of LED lighting can increase light pollution [7], [8], ecological impacts [9], and environmental degradation [10]. Old lighting technology, such as low pressure sodium (LPS) and HPS lighting, is claimed to be more beneficial from an astronomical and environmental perspective [7], [11], but cannot be dimmed and has a very low scotopic/photopic (S/P) ratio [12], indicating lower visibility. In [11] the new framework of sustainable indicators allow prioritization when choosing LED/SSL products and can thereby help ensure that short-term decisions on LED/SSL lighting systems are in line with long-term sustainability goals established in society. The aim of the paper is to propose a new method to evaluate the integral indicators of the efficiency of LED-based lighting. The purpose of this work is to study the influence of LED-based lighting on the organ of vision, and to estimate the efficiency of visual performance. 


\section{METHOD}

An important stage in the solution of tasks was the development of experimental research facility (ERF) for general lighting. Its detailed description is presented in [13]. Complex methodology, developed by us, for evaluation the impact of LED lighting conditions on the state of visual organ and the human body as a whole, was used in the research [7].

The analysis of existing methods for determining individual indicators made it possible to select the most appropriate tasks - to assess the effectiveness of LED lighting conditions when performing visuallyintense work. So changes in the functional state of the organ of sight were evaluated on the basis of examination:

a. accommodative-muscular apparatus of the organ of vision

b. receptor apparatus of the visual organ

c. central core of the organ of sight

Before the beginning of the research, a group of volunteer students aged 20 to 25 years was examined at the Republican Ophthalmologic Hospital in Saransk. This examination included: the definition of refraction; definition of visual acuity; computer tomography scan of retina. All selected persons had emmetropic refraction (predominantly), the visual acuity of both eyes was 1.0, the color perception without pathology.

60 selected observers were randomly divided into two groups, consisted of 30 persons: control group (experiment with fluorescent lights) and the main one (experiment with LED lights). The number of observers and the number of experiments were determined on the basis of requirements for obtaining statistically reliable data and time scheduling. Plan of experiment and work schedules for each group were compiled, taking into account daily biorhythms. Functional load was a one and a half hour visual-intensive work of a proof-reading type with paper texts; the work included mental component (calculation of the areas of curvilinear figures).

In all studied variants of lighting, quality indicators of illumination did not exceed the normalized values: unified glare rating (UGR) was in the range 10-14; the percent flicker was $0.2-0.6 \%$. Before the beginning of experimental studies, all the observers passed 10- days training in the research methods, until stable results were obtained. After the end of experimental research, control and main groups of observers underwent a second examination at the Republican Ophthalmologic Hospital in Saransk to determine whether the LED light causes a negative impact on the organ of vision.

The plan of experiment provided the measurement of absolute accommodation volume, the time of achromatic adisparopy, CFFF (on KPFK-99 "Psikhomat"), control of arterial blood pressure, before and after visual performance, under given lighting conditions. At the end of the work, observers completed up the questionnaires of subjective assessment of lighting conditions. For these studies, we developed a special questionnaire of subjective evaluation. It included questions about the main characteristics of lighting variant (LED and FL lighting), color rendering properties of emission, and psychoemotional state of the observers. In addition, chromatic thresholds (with the help of anomaloscope AN-59), and projections of blind spot of the organ of vision (according to the method of campimetry), were measured monocularly in the observers, before the beginning of visual-intense work and after its termination [8].

\section{RESULTS AND DISCUSSION}

In accordance with the requirements [14], LED lights (type Cap Flat 66-16 of joint Russian-Korean enterprise LLC "NEPES RUS" and type DVO 12-38-001 Prizma OJSC "Ardatov Lighting Plant"), and fluorescent lights (type LVO 04-4 × 14-041 PRS) were chosen for the experimental research facility. The values of correlated color temperature (CCT) are 3000, 4000 and $5000 \mathrm{~K}$. Photometric and spectrocolorimetric parameters of the selected lights were measured in the Common Use Center "Lighting metrology" of Federal State Budget Educational Institution of Higher Professional Education "Ogarev Mordovia State University". Figures 1-4 shows the emission spectra, light intensity curves and color rendering index $R_{a}$. 


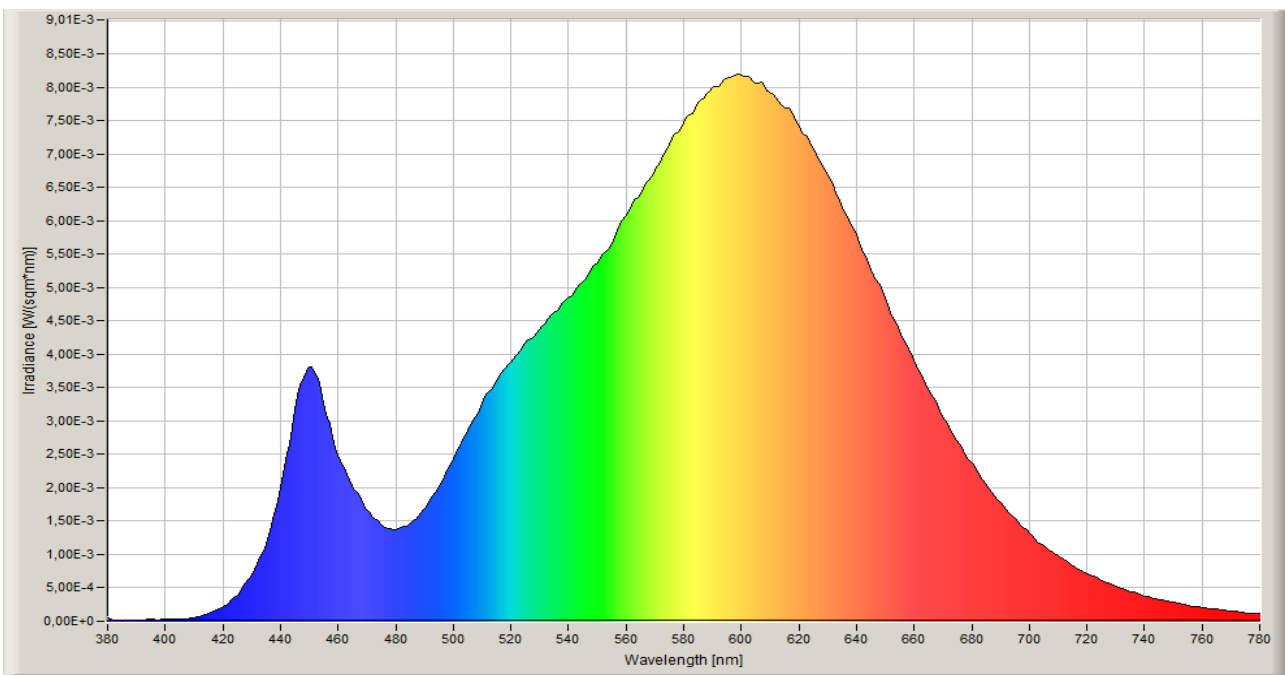

(a)

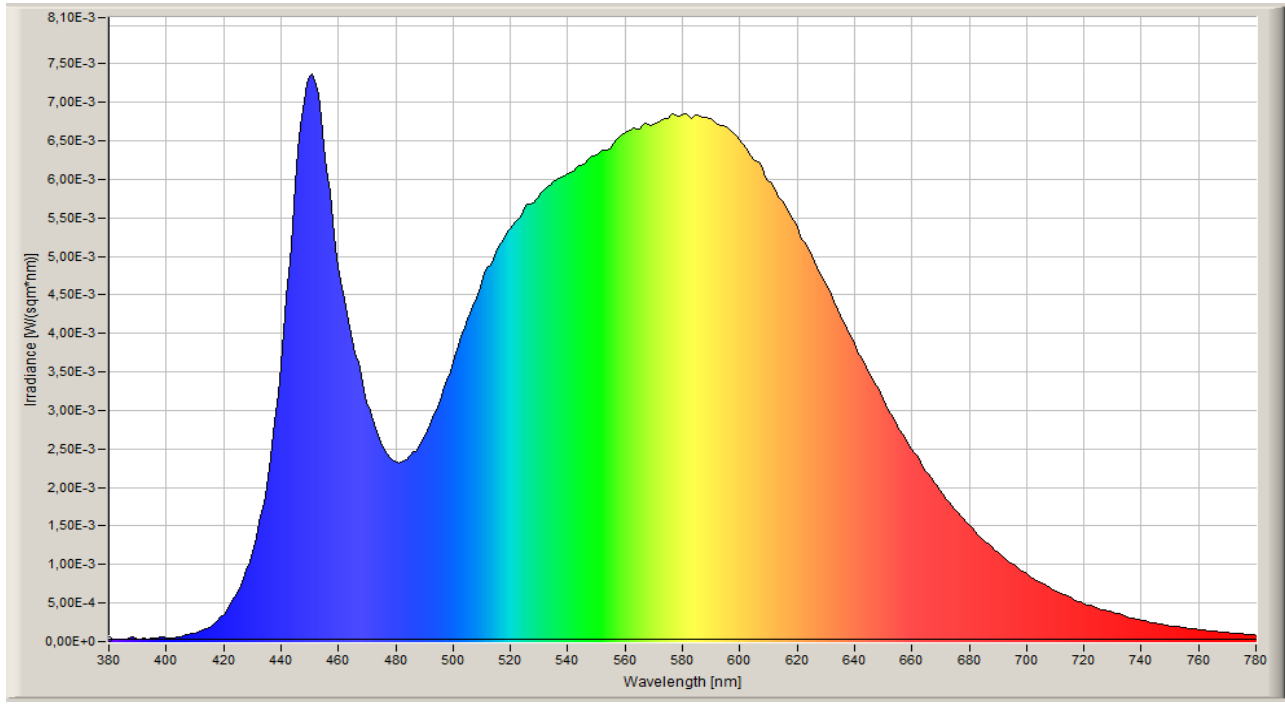

(b)

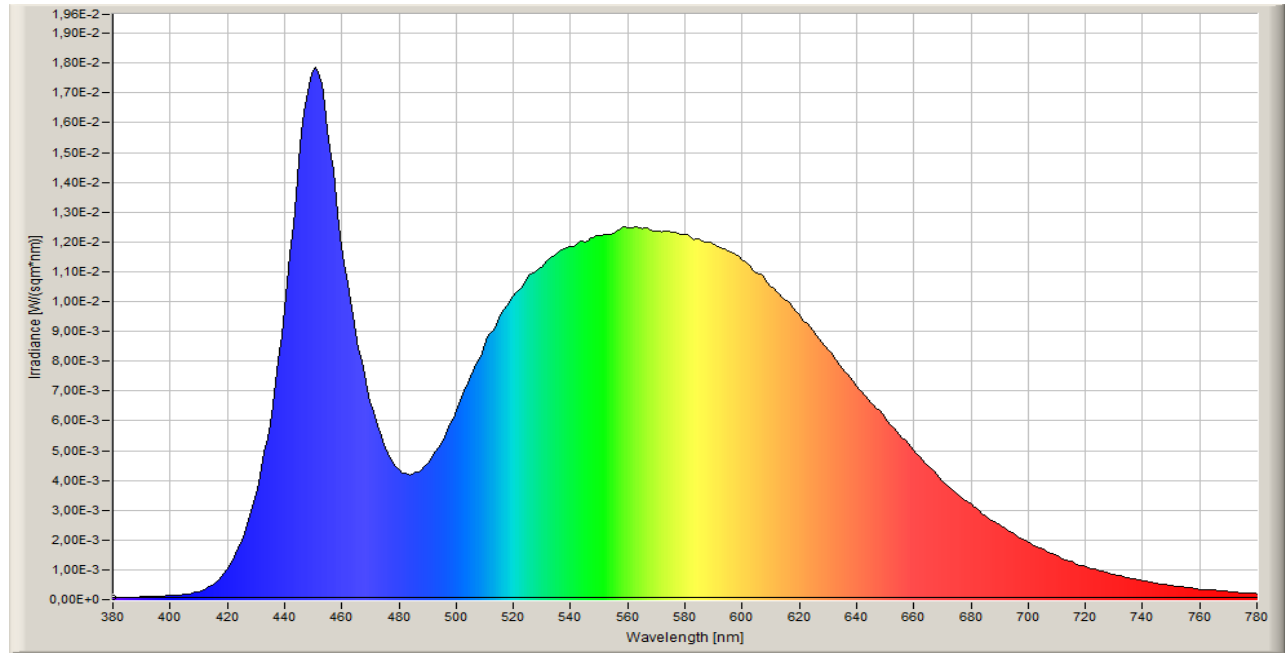

(c)

Figure 1. Emission spectra of LED lights: a) Cap flat 66-16 (LLC "NEPES RUS"), CCT $3000 \mathrm{~K}$; b) Cap flat 66-16 (LLC "NEPES RUS"), CCT $4000 \mathrm{~K}$ - LEDs produced by LLC "NEPES RUS"; c) DVO 12-38-416

(OJSC "ardatov lighting plant"), CCT $5000 \mathrm{~K}$, (LEDs produced by seoul semiconductor) 


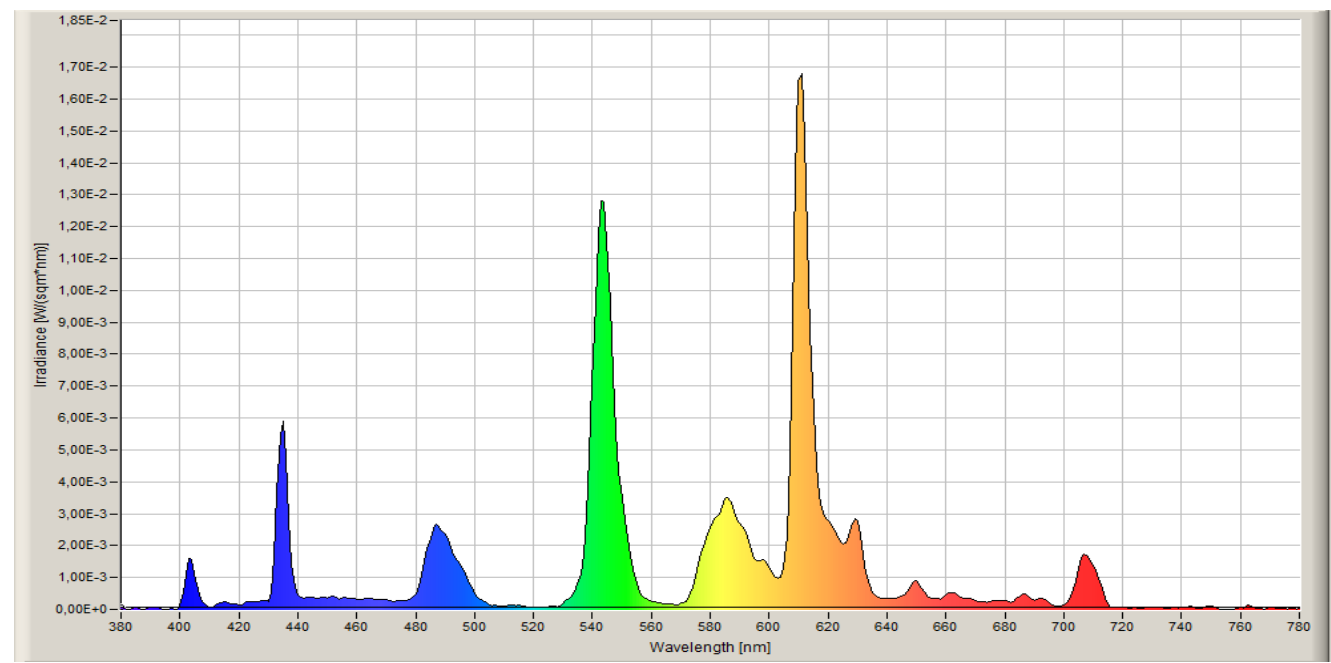

(a)

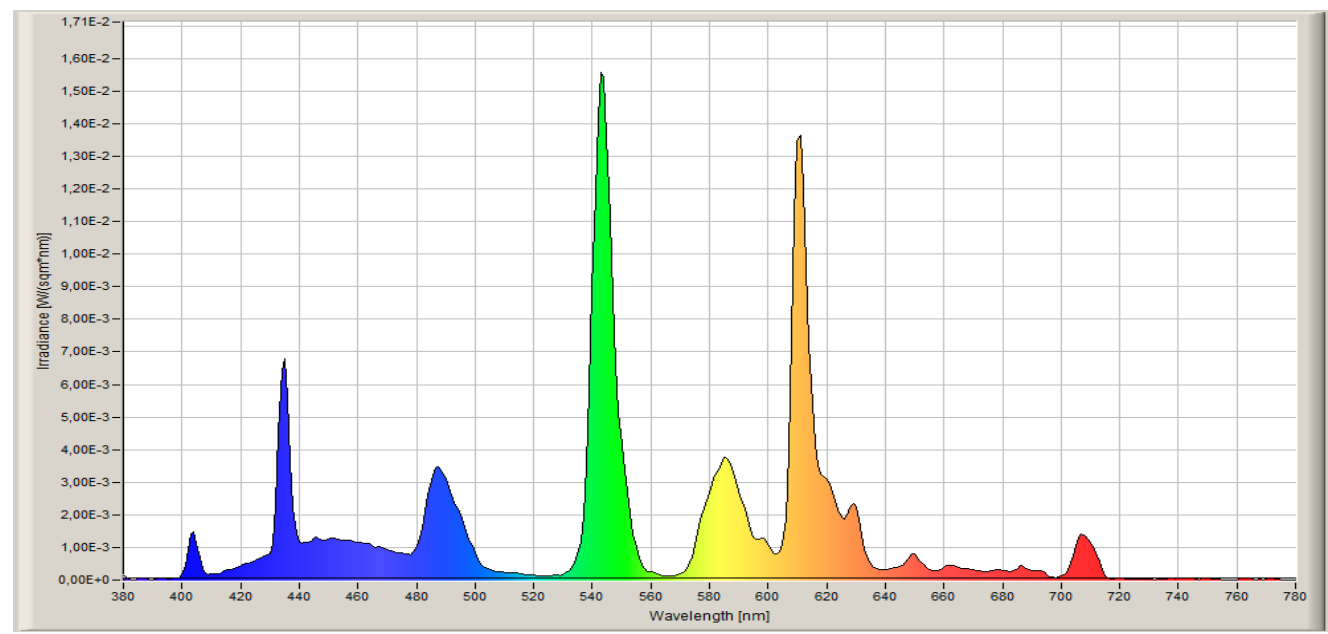

(b)

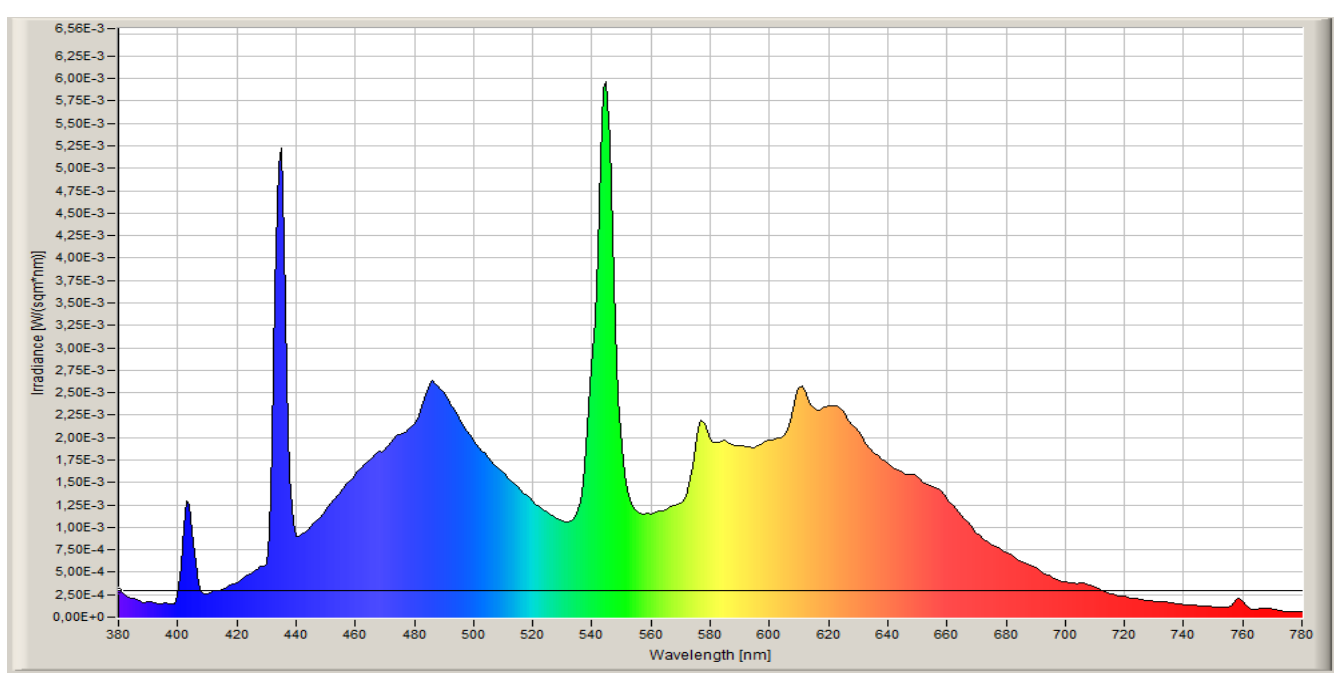

(c)

Figure 2. Emission spectra of fluorescent lights: a) LVO 04-4 × 14-041 PRS with fluorescent lamp T5 FH 14W HE (Osram), CCT 3000 K; b) LVO 04-4 × 14-041 PRS with fluorescent lamp master TL5 HE 14W (Philips), CCT $4000 \mathrm{~K}$ 


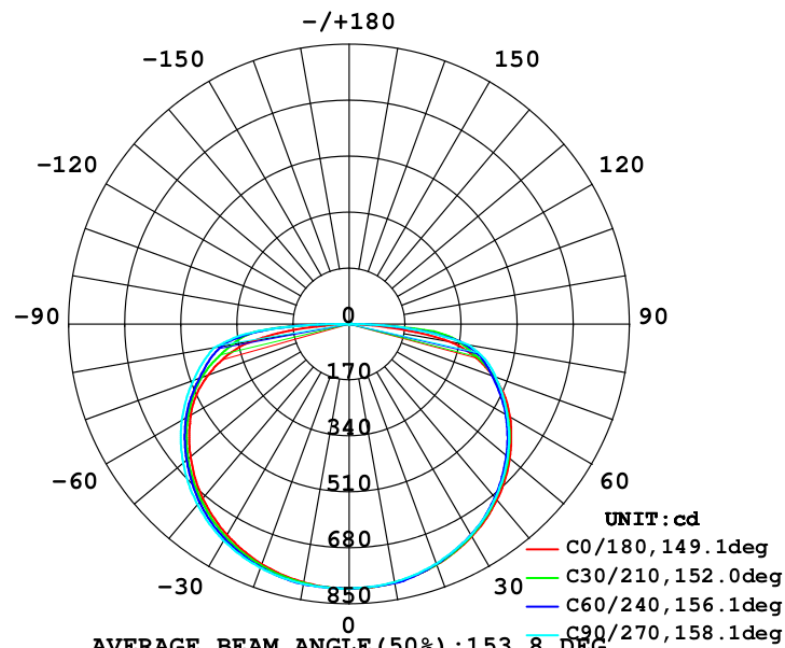

(a)

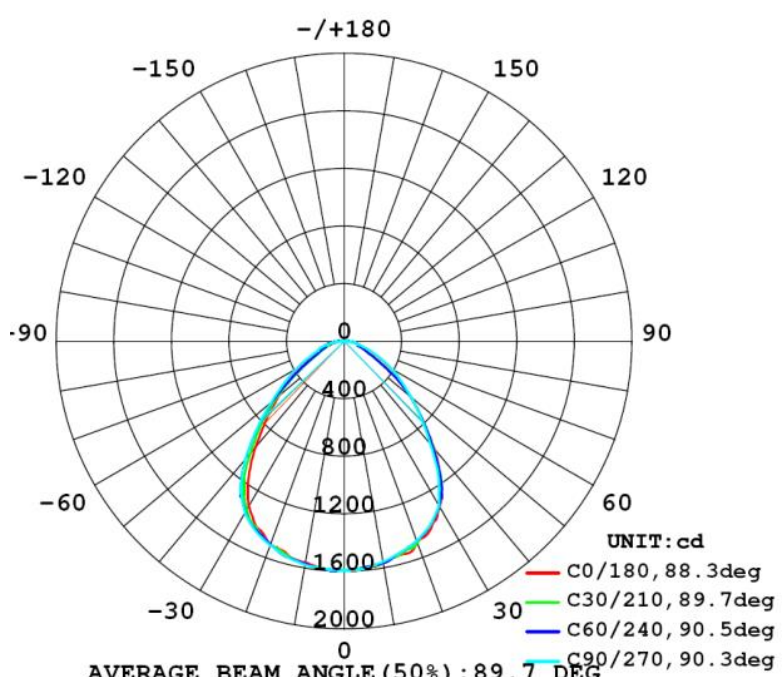

(b)

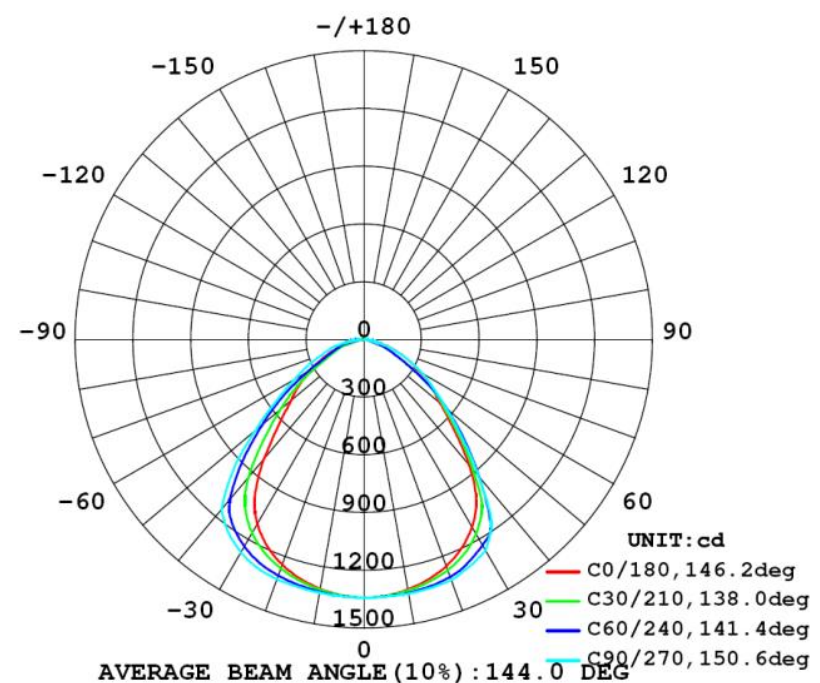

(c)

Figure 3. Light intensity curves of studied lights in four meridian planes: a) Cap Flat 66-16; b) DVO 12-38416; c) LVO 04-4 × 14-041 PRS with FL T5 


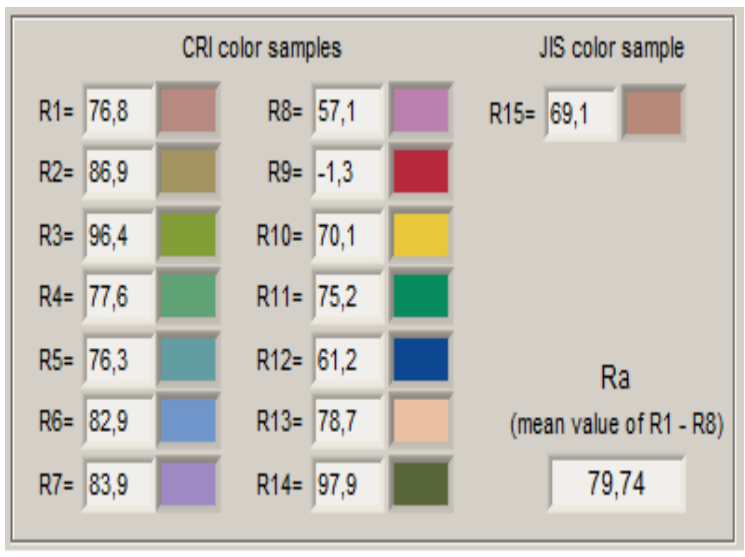

(a)

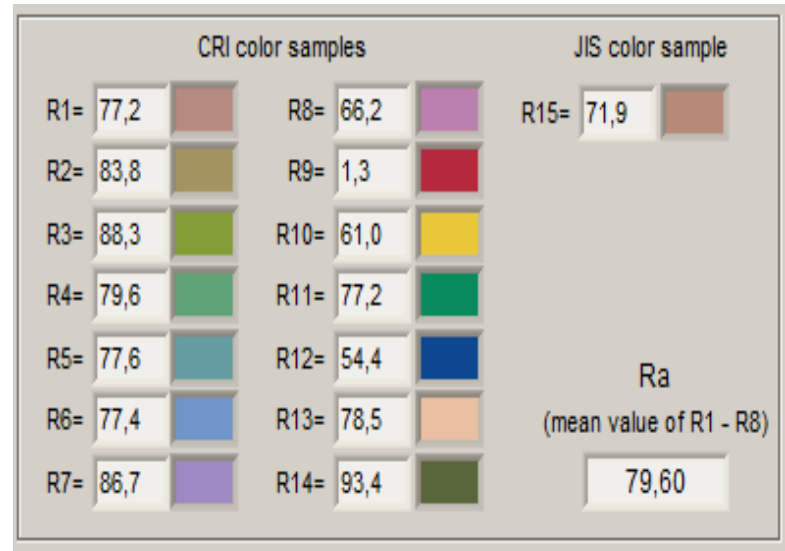

(b)

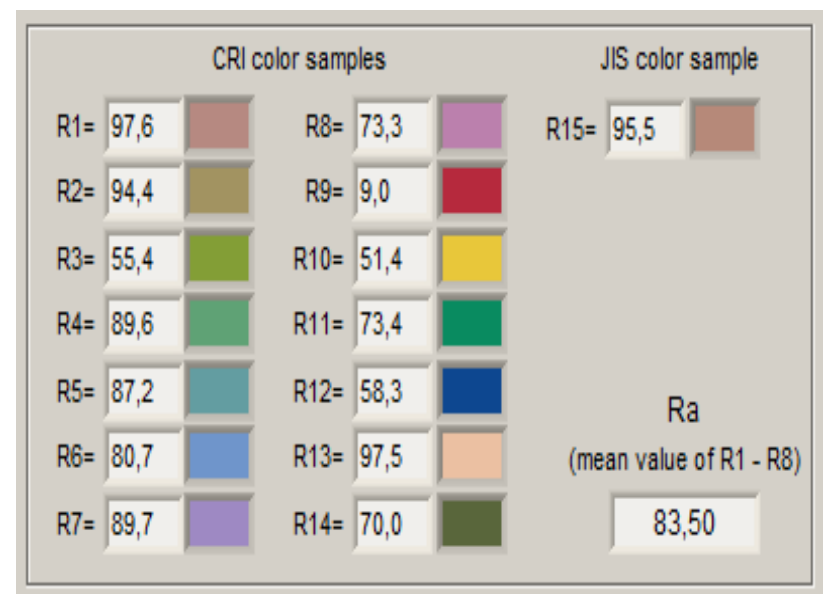

(c)

Figure 4. Color rendering indices of lights: a) type Flat 66-16; b) type DVO 12-38-416; c) type LVO 04-4 × 14-041 PRS with FL T5 master TL5 HE 14W/840, Philips

Change in the illumination level E of the working surface was achieved using electronic control gear PRA and drivers (according to protocol Digital Addressable Lighting Interface, (DALI)). Studies were carried out at three levels E: 200, 400 and 1000 lux.

Examinations of the organ of sight. Investigations of the volume of absolute accommodation (VAA) showed that in the process of intense visual performance its values decreased in all considered variants of illumination (Tables 1 and 2).

Table 1. Change in the Volume of Absolute Accommodation After Visual Performance in Different Variants

\begin{tabular}{|c|c|c|c|c|c|c|c|}
\hline \multirow[b]{2}{*}{ E, lux } & \multirow[b]{2}{*}{$\mathrm{CCT}, \mathrm{K}$} & \multicolumn{2}{|c|}{ Before visual performance } & \multicolumn{2}{|c|}{ After visual performance } & \multicolumn{2}{|c|}{ Correlation coefficient } \\
\hline & & $\begin{array}{c}\text { VAA, } \\
\text { diopters, } \bar{x}\end{array}$ & $\begin{array}{c}\text { Confidence } \\
\text { interval, } t \cdot \sigma_{\bar{x}}\end{array}$ & $\begin{array}{c}\text { VAA, } \\
\text { diopters, } \bar{x}\end{array}$ & $\begin{array}{c}\text { Confidence } \\
\text { interval, } t \cdot \sigma_{\bar{x}}\end{array}$ & $\begin{array}{l}\text { r (between before } \\
\text { and after work) }\end{array}$ & $\mathrm{p}(\mathrm{r})$ \\
\hline 200 & & 8.70 & 0.10 & 8.40 & 0.21 & 0.75 & $\mathrm{p}<0.05$ \\
\hline 400 & 3000 & 9.00 & 0.21 & 8.80 & 0.12 & 0.85 & $\mathrm{p}<0.01$ \\
\hline 1000 & & 9.90 & 0.16 & 9.70 & 0.19 & 0.73 & $\mathrm{p}<0.05$ \\
\hline 200 & & 9.40 & 0.13 & 9.00 & 0.16 & 0.66 & $\mathrm{p}<0.05$ \\
\hline 400 & 4000 & 9.70 & 0.17 & 9.50 & 0.19 & 0.65 & $\mathrm{p}<0.05$ \\
\hline 1000 & & 10.10 & 0.13 & 10.20 & 0.18 & 0.14 & - \\
\hline 200 & & 9.30 & 0.11 & 8.70 & 0.15 & 0.79 & $\mathrm{p}<0.05$ \\
\hline 400 & 5000 & 9.70 & 0.13 & 9.40 & 0.18 & 0.66 & $\mathrm{p}<0.05$ \\
\hline 1000 & & 10.00 & 0.22 & 9.80 & 0.24 & 0.63 & $\mathrm{p}<0.05$ \\
\hline
\end{tabular}


Table 2. Change in the Volume of Absolute Accommodation After Visual Performance in Different Variants

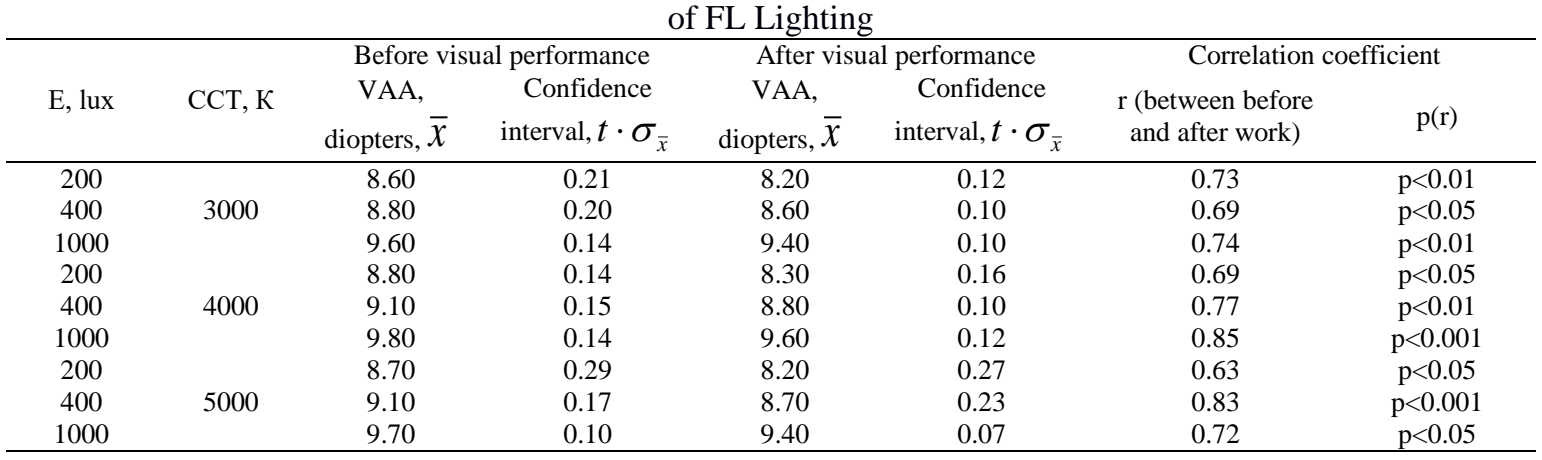

Determination of reliability of VAA changes, arising as a result of visual load, according to Student's t-test with $\mathrm{p}<0.05$, allowed to draw a conclusion that reliable changes in VAA were found practically in all variants of illumination. However, they do not exceed the limits of natural variations of this indicator of accommodative function of visual organ (0.5 - 1.5 diopters).

The assessment of spectral composition impact on the change in the studied accommodation indicator at constant E level, according to Student's t-test, is revealed in the compared variants at CCT 4000 $\mathrm{K}$, at all levels of E; and at CCT $5000 \mathrm{~K}$, at levels E 200 and 400 lux. The highest values of VAA were recorded in case of LED lighting. After visual performance in the conditions of LED lighting, in comparison with basic variant of illumination, the excess of VAA at CCT $4000 \mathrm{~K}$, in the range E $200-1000$ lx was 0.60.7 diopters (6.3-8.4\%); at CCT $5000 \mathrm{~K}$, in the range E $200-400$ lux it was $0.5-0.7$ diopters $(6.0-8.0 \%)$. So, it is established that the organ of vision is better accommodated in the conditions of LED lighting (at CCT $4000 \mathrm{~K}$ and $5000 \mathrm{~K}$ ). This is due to the greater activity of ciliary muscle and is probably related to the emission spectrum of LED.

The influence of CCT emission at constant E level on the change in time of achromatic adisparopy in the process of visual performance under the compared conditions is characterized by a high degree of relevance. The time of achromatic adisparopy, both before and after work, was longer in case of LED lighting. This indicates that LED lighting creates favorable conditions for the functions of accommodativemuscular apparatus of the organ of vision.

When assessing the state of retina according to the results of CT scan, it was found that in the observers of control and main groups the profile of foveola was preserved, the retina architectonics was not disturbed after the experiment. Statistical processing of examination results in both groups did not reveal statistically significant differences between the studied parameters ( $p>0.05$ according to Student's t-test). That is, the state of retina in observers remains without significant changes.

Investigation of the area of blind spot projection showed that retinal fatigue, estimated by the state of peripheral vision, leads to a significant increase in the physiological area of blind spot after performing intense visual work. The range of increase in the projection of optic nerve disk, in relation to the basic in case of FL illumination, was $6.57 \div 12.06 \%$; for LED lighting $-3.87 \div 10.77 \%$. Comparison of the dynamics of studied indicator revealed that at CCT $3000 \mathrm{~K}$, LED lighting contributes to a lesser visual fatigue (VF) in comparison with FL lighting $(\mathrm{p}<0.05)$.

In the course of experiment, it was found, that chromatic threshold changed variously in different conditions of illumination. As it follows from the obtained results, in the process of visual performance under conditions of LED and FL lighting, the functional state of retina is not the same. Probably, this is connected with photochemical reactions in retina, which can be inhibited and amplified by light emissions in various parts of visible spectrum. The impact of LED emission was detected only on the s-receptor of retina for emission with CCT $4000 \mathrm{~K}$ at E 1000 lux and CCT $5000 \mathrm{~K}$ at E 400 and $1000 \mathrm{~lx}$ (p <0.05). For other variants of illumination, the impact of light sources emissions on k-, z-, s-receptors was insignificant. This can be explained by the nature of visual tasks - work with achromatic objects.

Studies of the state of sight organ central core before and after visual performance, using the method CFFF, did not allow to reveal the most preferable variant of illumination: the Student's t-test did not confirm the reliability of differences in the entire investigated range of E and CCT. Thus, it was established that the parameters of CFFF in different conditions of lighting (LED and FL) did not differ significantly. The results of investigations show that the decrease in CFFF in the course of experiment is related to the visual performance. This process was reversible - by the beginning of the next day the indicators restored to their original values. That is, LED lighting did not exert inhibitory action on the state of CNS. 
Definition of integral indicators of LED lighting efficiency, according to visual performance and degree of visual fatigue. Visual performance was assessed using the method of correction tasks. Special tests - correction tasks - were applied in the conducted researches. They were created by using Cyrillic letters, and random number generator. The test contrast was negative. For two minutes, the observers worked with tests they deleted specified letter, which occurs in certain combinations. According to the test results, the coefficient of visual performance $I$ was calculated, taking into account the number of characters, scanned in the test, and the quality coefficient, taking into account correctly deleted characters and errors. The analysis of the research results of visual performance showed the advantages of LED lighting from the perspective of providing greater visual performance. The highest value of visual performance coefficient $I$ in conditions of LED lighting was established at CCT $4000 \mathrm{~K}$. Thus, in comparison with FL lighting at E 200 lux, it is higher by $11.8 \%$; at E 400 lux - by $14.9 \%$; at E 1000 lux - by $12.4 \%$.

Paired correlation coefficient $r$ confirmed $(\mathrm{p}<0.05)$ the presence of positive relationship between VAA and $I$ after visual work. This allowed to assume that a certain contribution to the increase in the coefficient of visual performance in case of LED lighting was made by better function of the accommodative-muscular apparatus.

The research results of work quality have shown that in the process of visual load its indicator decreased. However, the reliability of decrease in the accuracy coefficient according to Student's t-test was found only under conditions of LED lighting at CCT $4000 \mathrm{~K}$ (E 400 and 1000 lux); at CCT $5000 \mathrm{~K}$ (E 400 lux). When comparing the variants of lighting (LED and FL), differences in the quality of work were insignificant. Visual fatigue was assessed according to the dynamics of time threshold of achromatic adisparopy. At the same time, the parameter of visual fatigue was calculated as follows:

$$
A=\left(1-\frac{t_{j}}{t_{i}}\right) \cdot 100 \%
$$

where; A=visual fatigue, $\%$;

$t_{j}=$ time of achromatic adisparopy after visual performance, sec.;

$t_{i}=$ time of achromatic adisparopy before visual performance, sec.

It was established that lesser visual fatigue developed under the conditions of LED lighting, in the process of hour and a half visually-intense work. The lowest VF in case of LED lighting was noted for CCT $4000 \mathrm{~K}$ and $5000 \mathrm{~K}$ at $\mathrm{E} 400$ lux. The reliability of CCP influence on VF was proved in all the studied conditions of illumination with $\mathrm{p}<0.05$, according to Student's t-test.

\section{CONCLUSION}

Based on the results of experimental studies, it is established that LED-based lighting does not cause a negative impact on the organ of vision and the human body as a whole. The changes in the functional parameters of the organ of sight, which occur during the visual performance has the corresponding limits of physiological fluctuations and are reversible. The analysis of integral indicators of lighting efficiency for visual performance showed that LED lighting conditions contributed to providing higher visual performance and lesser visual fatigue.

The analysis of the results of experimental studies has reliably shown that LED lighting does not have a negative impact on the organ of sight and visual performance indicators (age group $20-25$ years). Studies, carried out under different lighting conditions (LED and FL) revealed a close relationship of vision functions with compensatory-adaptive response of the organism and the stability of adaptive systems, responsible for the regulation of sensitivity of visual organ and the organism as a whole. The results of the research can be used to develop practical recommendations for the use of LED-based lighting systems. In conclusion, it should be noted, that the work on hygienic assessment of LED-based lighting requires continuation, including in the field of determining its efficiency for industrial lighting installations of various functional purposes.

\section{REFERENCES}

[1] Light environment for humans: science, industry and law // Lighting engineering. - 2016. - №1. - Pp. 45 - 49.

[2] Behar-Cohen, F., Martinsons, C., Vienot, F., Zissis, G., Barlier-Sals, A., Cesarini, J.P., Enouf, O., Garcia, M., Icaud, S., Attia, D., 2011. Light-emitting diodes (LED) for domestic lighting: Any risks for the eye? Journal of Progress in Retinal and Eye Research, 30: 239 - 257. 
[3] Wahnschaffe, A., Haedel, S., Rodenbeck, A, Stoll, C, Rudolph, H, Kozakov, R, Schoepp, H, Kunz, D., 2013. Evening Short-Term Exposure to Conventional Light Suppresses Melatonin and Increases Alertness Perception. International Journal of Molecular Sciences. 14: 2573 - 2589.

[4] Gooley, J.J., Chamberlain, K., Smith, K.A, Khalsa, S.B., Rajaratnam, S.M., van Reen, E., Zeitzer, J.M., Czeisler, C.A, Lockley, S.W., Clin, J, 2011. Exposure to room light before bed time suppresses melatonin onset and shortens melatonin duration in humans. Journal of Endocrinol. Metab, 96: 463-472.

[5] Vegter Klaas, 2012. The future of lighting:beyond saving energy. Conference on Optics for Solar Energy (SOLAR) at the Renewable Energy and the Environment Congress, Eindhoven, 11-14 Nov., Washington (D.C.), p: 83.

[6] Kawasaki, S., Horikoshi, Y., Yainazaki, A., Kasahara, K., 2012. Impact of two competing energy transfer mechanisms on spectra in organic light emitting diodes. Conference on Optics for Solar Energy (SOLAR) at the Renewable Energy and the Environment Congress, Eindhoven, 11-14 Nov., Washington (D.C.), pp: 64-65.

[7] Falchi, F.; Cinzano, P.; Elvidge, C.D.; Keith, D.M.; Haim, A. Limiting the impact of light pollution on human health, environment and stellar visibility. J. Environ. Manag. 2011, 92, 2714-2722.

[8] Bierman, A. Will switching to LED outdoor lighting increase sky glow? Light. Res. Technol. 2012, 44, 449-458.

[9] Pawson, S.M.; Bader, M.K.F. LED lighting increases the ecological impact of light pollution irrespective of color temperature. Ecol. Appl. 2014, 24, 1561-1568.

[10] Lyytimäki, J. Nature's nocturnal services: Light pollution as a non-recognised challenge for ecosystem services research and management. Ecosyst. Serv. 2013, 3, 44-48.

[11] De la Paz Gómez, F.; Sanhueza, P.; Castro, J.D. Practical Guide for Outdoor Lighting. Efficient Lighting and Control of Light Pollution. Available online:http://www.iac.es/adjuntos/otpc/ opcc-otpc_guide.pdf (accessed on 11 November 2014).

[12] Boyce, P. Lighting for Driving: Roads, Vehicles, Signs and Signals; CRC Press, Taylor and Francis Group: Boca Raton, FL, USA, 2009.

[13] Zheleznikova, O., Amelkina S., 2015. Experimental Research facility with LED lights. Research Journal of Pharmaceutical, Biological and Chemical Sciences. 6(2): 94-99.

[14] Annika K. Jägerbrand, New Framework of Sustainable Indicators for Outdoor LED (Light Emitting Diodes) Lighting and SSL (Solid State Lighting), Sustainability 2015, 7, 1028-1063; doi:10.3390/su7011028.

[15] GOST R 54350-2015. Light devices. Light requirements and test methods.

[16] Zheleznikova, O.E. Development of comprehensive methodology for assessment the impact of LED-based lighting conditions on the state of the visual organ and the human body as a whole / O.E. Zheleznikova, S.A. Amelkina, L.V. Sinitsyna, S.V. Kiryukhina // Natural and technical sciences. - 2013. - № 5 (67). - Pp. 249 - 257.

[17] S.V. Aksenova, M.P. Kulikova, O.E. Zheleznikova, L.V. Sinitsyna, S.A. Amelkina Method for the determining of visual fatigue: Pat. 2534910 the Russian Federation IPC 7 A 61 B 3/02 /; applicant and patent holder - Federal State Budget Educational Institution of Higher Professional Education "Ogarev Mordovia State University” - № 2013145991; applic. 16.10.13; publ. 10.12.14, Bul. №34. - 10p 